\title{
Low Back Pain among Medical Students in Belgrade (Serbia): A Cross-Sectional Study
}

\author{
Isidora Vujcic $\mathbb{D}^{1}{ }^{1}$ Nemanja Stojilovic, ${ }^{1}$ Eleonora Dubljanin, ${ }^{2}$ Nebojsa Ladjevic, ${ }^{3}$ \\ Ivana Ladjevic, ${ }^{4}$ and Sandra Sipetic-Grujicic ${ }^{1}$ \\ ${ }^{1}$ Institute of Epidemiology, Faculty of Medicine, University of Belgrade, Belgrade, Serbia \\ ${ }^{2}$ Institute of Microbiology and Immunology, Faculty of Medicine, University of Belgrade, Belgrade, Serbia \\ ${ }^{3}$ Institute of Urology and Nephrology, Clinical Center of Serbia, Belgrade, Serbia \\ ${ }^{4}$ Clinic for Obstetrics and Gynecology, Clinical Center of Serbia, Belgrade, Serbia \\ Correspondence should be addressed to Isidora Vujcic; isidoravujcic@yahoo.com
}

Received 6 October 2017; Accepted 19 December 2017; Published 6 February 2018

Academic Editor: Jacob Ablin

Copyright (c) 2018 Isidora Vujcic et al. This is an open access article distributed under the Creative Commons Attribution License, which permits unrestricted use, distribution, and reproduction in any medium, provided the original work is properly cited.

\begin{abstract}
Aim. To examine the prevalence of low back pain, to identify self-perceived triggers of low back pain, and to investigate the impact of perceived pain on the daily activities and mood among medical students. Methods. This cross-sectional study enrolled 459 fourth year students at the Faculty of Medicine in Belgrade during December 2014. The anonymous questionnaire was used for data collection. In data analysis, the chi-square test and $t$-test were used. Results. The lifetime prevalence of low back pain was $75.8 \%, 12$-month prevalence $59.5 \%$, and point prevalence $17.2 \%$. Chronic low back pain was experienced by $12.4 \%$ of the students. Both the lifetime $(p=0.001)$ and the 12-month $(p=0.001)$ low back pain prevalence rates were significantly higher among female medical students. Mental stress during an exam period $(p=0.001)$, sitting at the university $(p=0.002)$, fatigue $(p=0.043)$, improper body posture $(p=0.005)$, and lack of exercise $(p=0.001)$ as self-perceived triggers of low back pain were significantly more often reported by female students, compared to males. Regarding daily functioning, the experience of low back pain mostly affects students sleeping (14.6\%) and walking (12.0\%). Conclusions. The prevalence of LBP is high among Belgrade medical students and significantly affects their everyday functioning.
\end{abstract}

\section{Introduction}

Low back pain (LBP) is one of the most common health problems and affects people of all ages, from children to the elderly $[1,2]$. According to the Global Burden of Disease 2010 Study, the prevalence and burden of LBP are very high throughout the world [3]. Out of the 291 conditions studied, LBP was found to have the sixth highest burden and to cause more disability globally than any other condition [3]. In 2010, the age-standardized point prevalence was highest in Western Europe (15\%) and North Africa/Middle East (14.8\%). The age-standardized point prevalence in Central Europe, including Serbia, was $11.5 \%$ (12.6\% in males and $10.3 \%$ in females) and ranked the fifth place [3]. However, it is estimated that over $80 \%$ of the population will experience an episode of LBP at some time during life, and that about $18 \%$ of the population experience LBP at any given moment [4].
The main risk factors for LBP are age, gender, obesity, psychosocial factors (stress, anxiety, and depression), level of education, occupational factors, decreased flexibility and mobility of muscles, hypermobility, competition sports, type and way of carrying and transporting weight, postural habits, level of physical activity, smoking, and domestic factors such as watching TV and computer/videogame [5, 6]. LBP often begins in childhood, and the prevalence rate for adolescents approaches that seen in adults [7]. Epidemiological studies have shown an increase in LBP in children, teenagers, and young adults [8], but studies exhibit great variability in prevalence rates [7]. It is challenging to compare the prevalence of LBP between populations and over time due to methodological heterogeneity across studies such as the age of the sample, the sample size, the definition of LBP, the LBP recall period, the strategy for extracting data, the methodology used, and difficulties in obtaining true population estimates $[6,7]$. 
TABle 1: Prevalence of low back pain among male and female medical students.

\begin{tabular}{|c|c|c|c|c|}
\hline Characteristics & $\begin{array}{l}\text { All students } \\
\quad(n=459) \\
\text { Number }(\%)\end{array}$ & $\begin{array}{c}\text { Males } \\
(n=156) \\
\text { Number }(\%)\end{array}$ & $\begin{array}{c}\text { Females } \\
(n=303) \\
\text { Number }(\%)\end{array}$ & $p$ value \\
\hline Age $(x \pm \mathrm{SD})$ (years) & $22.46 \pm 0.95$ & $22.45 \pm 1.02$ & $22.46 \pm 0.91$ & $0.859^{*}$ \\
\hline \multicolumn{5}{|l|}{ Place of living } \\
\hline Belgrade & $179(39)$ & $61(39.1)$ & $118(38.9)$ & $1.000^{* *}$ \\
\hline Others & $280(61)$ & $95(60.9)$ & $185(61.1)$ & \\
\hline \multicolumn{5}{|c|}{ Lifetime prevalence of LBP } \\
\hline Yes & $348(75.8)$ & $103(66.0)$ & $245(80.9)$ & $0.001^{* *}$ \\
\hline \multicolumn{5}{|c|}{ The 12-month prevalence of LBP } \\
\hline Yes & $273(59.5)$ & $74(47.4)$ & $199(65.7)$ & $<0.001^{* *}$ \\
\hline \multicolumn{5}{|c|}{ Point prevalence of LBP } \\
\hline Yes & $79(17.2)$ & $28(17.9)$ & $51(16.8)$ & $0.795^{* *}$ \\
\hline \multicolumn{5}{|c|}{ Chronic LBP (pain persists 12 weeks or longer) } \\
\hline Yes & $57(12.4)$ & $15(9.6)$ & $42(13.9)$ & $0.232^{* *}$ \\
\hline
\end{tabular}

${ }^{*}$ According to the $t$-test, ${ }^{* *}$ according to the chi-square test, LBP: low back pain.

Some studies reported a high prevalence of LBP among medical students [9-11]. Due to highly demanding curriculum during the studies, medical students are exposed to stress, sedentary lifestyle, and long hours on hospital wards and clinics which may lead to the high prevalence of LBP in this population. Also, the presence of LBP can affect medical students' productivity, their attendance at lectures and medical training, and therefore their future career. Higher prevalence of LBP was observed among students with five or more semesters, suggesting that advanced students who most often are exposed to practical activities are at increased risk for disease [12].

The aims of this study were to examine the prevalence of LBP (lifetime, 12-month, and point prevalence) among Belgrade clinical medical students, to identify self-perceived triggers of LBP, and to investigate the impact of perceived pain on their daily activities and mood.

\section{Participants and Methods}

2.1. Study Participants. A cross-sectional study was conducted in December 2014 among fourth year students at the Faculty of Medicine in Belgrade. The study was approved by Institutional Review Board of the Faculty of Medicine, University of Belgrade. Students were recruited before the start of compulsory practical sessions at the Institute of Epidemiology. The purpose of the study and questionnaire's content were described to the students. A total 459 of all 533 fourth year medical students completed the questionnaire fully (response rate was $86.12 \%$ ).

2.2. Questionnaire. Each student had to fill out an anonymous questionnaire that included questions regarding the following: demographic characteristics (age, gender, and place of living), the prevalence of LBP (lifetime, 12-month, and point prevalence) and chronic LBP, self-perceived triggers of LBP (stress at the university during the exam period, sitting at the university, uncomfortable mattress, and improper body posture), the impact of pain on daily functioning (sleeping, walking, and everyday activities), and the impact of pain on mood (anger and anxiety). In order to assess self-perceived triggers of LBP and the impact of pain on daily functioning and mood, a numerical rating scale was used ranging from zero (no impact) to six (extremely strong impact). To facilitate data analysis, we collapsed responses to no impact, small/moderate impact, and strong/extremely strong impact. For students, LBP was defined as pain in the area between the inferior margin of the 12th rib and inferior gluteal folds $[3,13]$. The lifetime prevalence was estimated as the proportion of respondents who had ever suffered LBP at some point in their lives. The 12-month prevalence referred to the presence of LBP in the last year, and the point prevalence referred to the presence of LBP at the moment of filling out the questionnaire (currently). We classified LBP as chronic if it was present for more than 12 weeks.

2.3. Statistical Analysis. Statistical differences between male and female students were tested using the chi-square test and $t$-test. A $p$ value of $<0.05$ was considered statistically significant.

\section{Results}

3.1. Prevalence of Low Back Pain. The mean age of study participants was 22.46 years $(\mathrm{SD} \pm 0.95)$, and two-thirds (66.0\%) were female students. Out of 459 investigated students, $75.8 \%$ reported LBP at some point in their lives, $59.5 \%$ in the last 12 months, and $17.2 \%$ of them were suffering from LBP at the moment they were surveyed (Table 1). Chronic LBP reported $12.4 \%$ of the students. The lifetime and 12-month prevalence of LBP were significantly higher among female than male medical students, while the point prevalence was similar in both groups.

3.2. Self-Perceived Subjective Triggers of LBP. The most often cited self-perceived subjective triggers with strong/extremely 


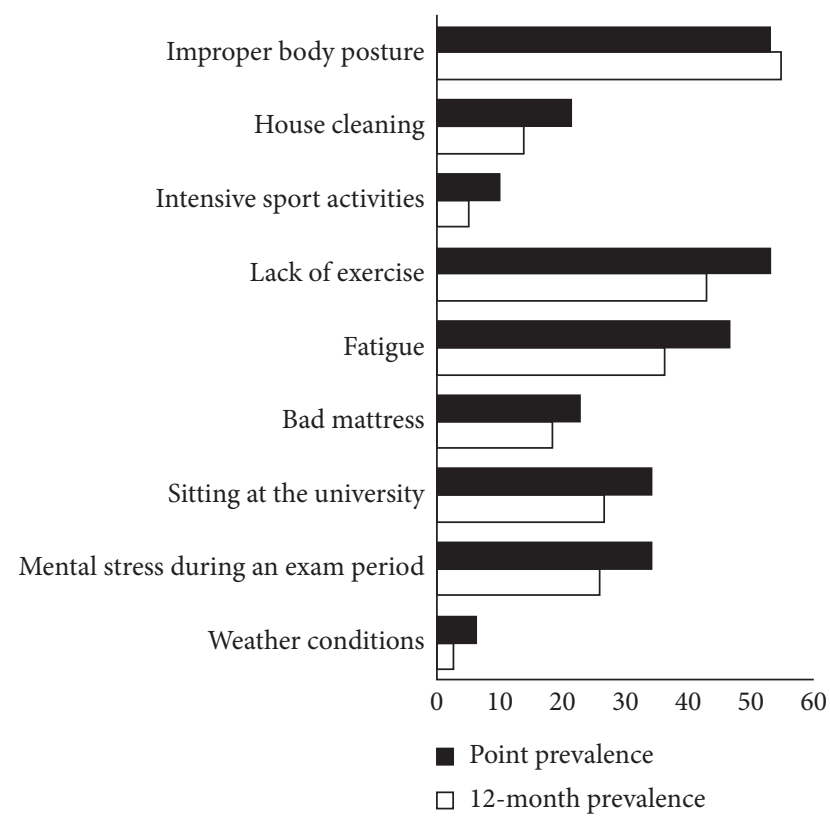

FIGURE 1: Self-perceived subjective triggers with strong/extremely strong impact on low back pain among medical students.

strong impact on the point and 12-month LBP prevalence were the following, respectively: improper body posture (53.3\% versus $54.9 \%$ ), lack of exercise (53.2\% versus $42.9 \%$ ), and fatigue (46.8\% versus $36.3 \%$ ). Mental stress during an exam period and sitting at the university as potential triggers for currently present LBP reported about one-third of the investigated students (34.2\%) (Figure 1). Other reported triggers were bad mattress, house cleaning, intensive sport activities, and weather conditions.

Statistically significant gender difference regarding selfperceived subjective triggers of LBP was found for mental stress during an exam period, sitting at the university, fatigue, lack of exercise, and improper body posture which were reported more often by female students (Table 2).

3.3. The Impact of LBP on Everyday Functioning and Mood. Regarding everyday functioning, LBP mostly affects students sleeping (14.6\%) and walking (12.0\%) (Figure 2), while personal interrelationships are less likely affected by the presence of LBP. Similar findings were observed for the presence of LBP currently and in the previous 12 months.

The most medical students cited that the presence of LBP currently and in the last year annoys them and makes them angry and worry (Figure 3).

\section{Discussion}

According to the results of our study, the point prevalence of LBP among Belgrade medical students was 17.2\%, 12-month prevalence $59.5 \%$, and lifetime prevalence $75.8 \%$. These findings are consistent with other studies, indicating that the point prevalence is less than the period prevalence and both are less than the lifetime prevalence $[1,7,14]$. The 12-month prevalence of LBP was $47.5 \%$ among students in India [9],
TABle 2: Self-perceived subjective triggers connected with occurrence of low back pain among medical students regarding their gender.

\begin{tabular}{|c|c|c|c|}
\hline Factors & $\begin{array}{c}\text { Males } \\
(n=156) \\
\text { Number } \\
(\%)\end{array}$ & $\begin{array}{c}\text { Females } \\
(n=303) \\
\text { Number } \\
(\%)\end{array}$ & $\begin{array}{c}p \\
\text { value* }\end{array}$ \\
\hline \multicolumn{4}{|l|}{ Weather conditions } \\
\hline Small/moderate impact & $16(15.5)$ & $61(24.9)$ & 0.153 \\
\hline $\begin{array}{l}\text { Strong/extremely strong } \\
\text { impact }\end{array}$ & $5(4.9)$ & $12(4.9)$ & \\
\hline \multicolumn{4}{|l|}{$\begin{array}{l}\text { Mental stress during an exam } \\
\text { period }\end{array}$} \\
\hline Small/moderate impact & $32(31.1)$ & $85(34.7)$ & $<0.001$ \\
\hline $\begin{array}{l}\text { Strong/extremely strong } \\
\text { impact }\end{array}$ & $20(19.4)$ & $91(37.1)$ & \\
\hline \multicolumn{4}{|l|}{ Sitting at the university } \\
\hline Small/moderate impact & $34(33.0)$ & $77(31.4)$ & 0.002 \\
\hline $\begin{array}{l}\text { Strong/extremely strong } \\
\text { impact }\end{array}$ & $23(22.3)$ & $99(40.4)$ & \\
\hline \multicolumn{4}{|l|}{ House cleaning } \\
\hline Small/moderate impact & 39 (37.9) & $82(33.5)$ & 0.555 \\
\hline $\begin{array}{l}\text { Strong/extremely strong } \\
\text { impact }\end{array}$ & $18(18.4)$ & $57(23.2)$ & \\
\hline \multicolumn{4}{|l|}{ Bad mattress } \\
\hline Small/moderate impact & $37(35.9)$ & $82(33.4)$ & 0.862 \\
\hline $\begin{array}{l}\text { Strong/extremely strong } \\
\text { impact }\end{array}$ & $36(25.3)$ & $68(27.8)$ & \\
\hline \multicolumn{4}{|l|}{ Fatigue } \\
\hline Small/moderate impact & $31(30.1)$ & $56(22.9)$ & 0.043 \\
\hline $\begin{array}{l}\text { Strong/extremely strong } \\
\text { impact }\end{array}$ & $33(32.0)$ & $114(46.5)$ & \\
\hline \multicolumn{4}{|l|}{ Lack of exercise } \\
\hline Small/moderate impact & $32(20.5)$ & $65(21.5)$ & $<0.001$ \\
\hline $\begin{array}{l}\text { Strong/extremely strong } \\
\text { impact }\end{array}$ & $43(27.6)$ & $136(44.8)$ & \\
\hline \multicolumn{4}{|l|}{ Improper body posture } \\
\hline Small/moderate impact & $27(26.2)$ & $51(20.8)$ & 0.005 \\
\hline $\begin{array}{l}\text { Strong/extremely strong } \\
\text { impact }\end{array}$ & $51(49.5)$ & $163(66.5)$ & \\
\hline
\end{tabular}

${ }^{*}$ According to the chi-square test.

46.1\% among Malaysian students [10], and 53.4\% among Austrian medical students [15]. In a Brazilian study, which included medical and physiotherapy students, the lifetime prevalence of LBP only among medical students was $73.4 \%$, 12 -month prevalence $59.9 \%$, and point prevalence $9.2 \%$, while physiotherapy students reported a higher prevalence of LBP when compared with the medical students in all measures [12]. The lifetime and 12-month prevalence of LBP observed in our study were similar to those of the Brazilian study, but the point prevalence of LBP in our study was significantly higher than that in the Brazilian study. Higher point prevalence in our study may be explained by the fact that, in our study, fourth year medical students who were on clinical training participated and higher prevalence of LBP was observed 


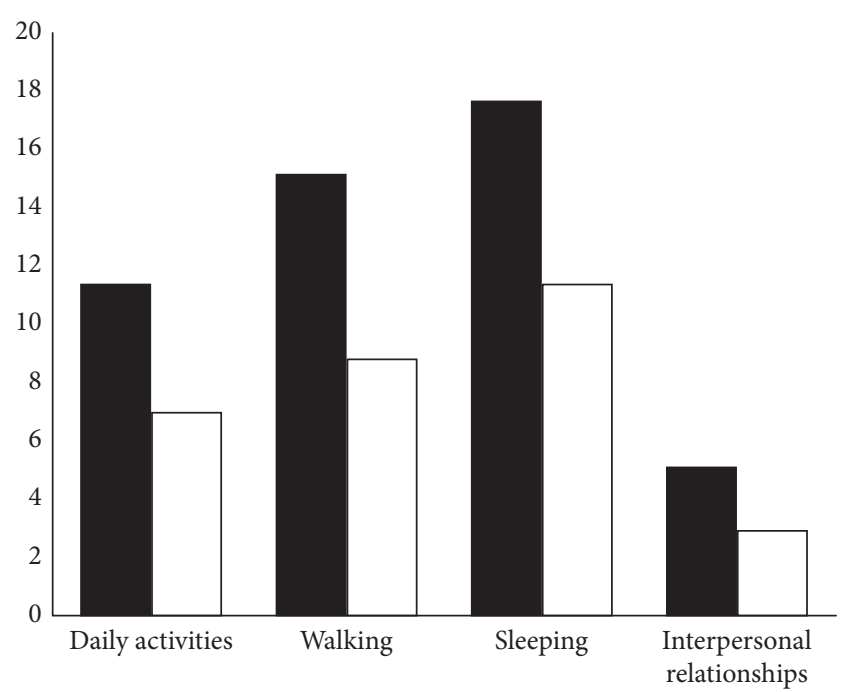

- Point prevalence

$\square$ 12-month prevalence

Figure 2: The impact of low back pain on medical students' everyday functioning.

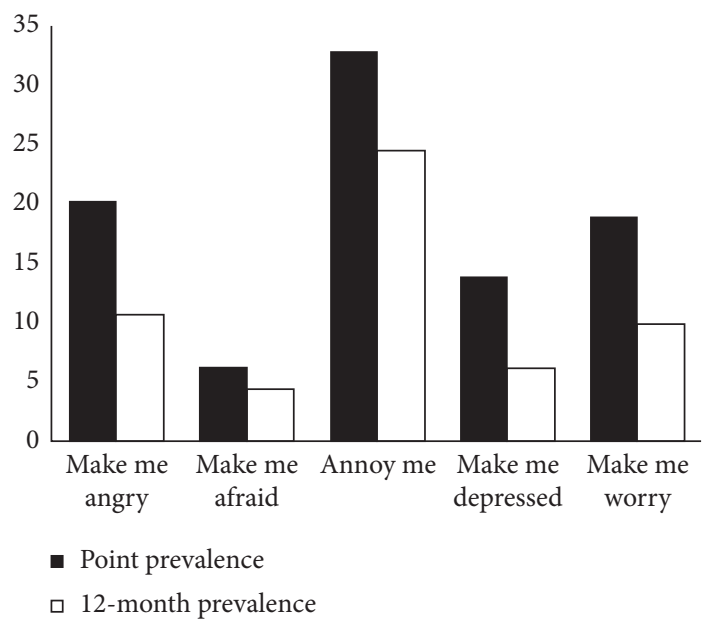

Figure 3: The impact of low back pain on medical students' mood.

among older medical students, who are exposed to practical activities as mentioned earlier. In the Brazilian study, more than half of the medical students (51.2\%) were preclinical, until the fourth semester. The Chinese study, conducted among fourth year medical students, as in our study, revealed a 12-month LBP prevalence of $40.1 \%$ and a point prevalence of $17.9 \%$ [11].

Female medical students in our study reported significantly higher 12-month and lifetime prevalence, compared to male students, while the point prevalence of LBP was similar in both genders; in fact, the rate was lower in female students. According to studies conducted among children and adolescents, girls have higher prevalence rates of LBP than boys [16, 17]; therefore, the lifetime LBP prevalence is expected to be higher in female students. Regarding studies conducted among medical students, most of the studies did not find the significant difference in the 12-month LBP prevalence between genders including the Chinese study [11], the study from India [9], and the Malaysian study as well, which investigated the prevalence of musculoskeletal pain including LBP too [10]. The Brazilian study compared the prevalence of LBP among medical and physiotherapy students, and the Austrian study compared the prevalence of LBP among the medical students and random sample of physical education students, and therefore they were not focused on the gender difference of LBP among medical students. In contrast, the Australian study found that female medical students, compared to males, 1.8 times more often reported LBP [18].

The most often cited self-perceived subjective triggers with strong/extremely strong impact on LBP occurrence in our study were improper body posture, lack of exercise, and fatigue. The study conducted among medical students in India [9] also showed that abnormal body posture was one of the factors independently associated with LBP. Although lack of exercise was reported as a risk factor for LBP in some studies $[19,20]$, there is still conflicting evidence on the potential association between physical activity and low back pain in both general population and school children [21]. Fatigue is a common complaint among medical students, and the study of Tanaka et al. [22] found that stress and coping styles were associated with severe fatigue in medical students. Medical students in our study reported fatigue as the third most often trigger of LBP.

However, female medical students, in comparison with male students, significantly more often reported mental stress during an exam period, sitting at the university, fatigue, lack of exercise, and improper body posture as potential triggers for LBP. In addition, the 12-month prevalence of LBP was significantly higher among female students. Taking into account that LBP is a multidimensional disorder, with physical, lifestyle, and psychosocial factors related to its development and maintenance [23], a possible explanation for these findings includes that female students, in comparison with males, are more emotionally sensitive and feel fatigued more easily [24]. Also, females have greater sensitivity to painful stimuli and lower pain thresholds compared to males [25]. The study conducted among Australian adolescents indicates that being female and sitting posture are related factors for LBP, and that greater proportion of female participants than male participants were complaining of back pain that was made worse by sitting [23], which is very similar to the results of our study. The sex relationship with posture may be related to sex differences in the shape of the pelvis, greater back muscle endurance in women, sex-specific motor activation patterns, inappropriate furniture at the university and hospitals, behavioral issues, and other social factors such as anxiety and depression [23].

Numerous studies showed that multiple domains of psychosocial functioning are affected by LBP experience such as social relationships, self-esteem, mood and affect, social roles, family duties, life satisfaction, and independence in satisfying one's own needs [26]. In our study among medical students, LBP mostly affects their sleeping quality and walking. The study conducted at four universities in Poland indicates that LBP interferes with or limits daily activities of the students, such as sitting, standing, 
or physical activity [27], and according to this study, LBP influences sleeping in $17.7 \%$ of participants and walking in $12.8 \%$ which is very similar to the results of our study. Also, LBP experience affects medical students' mood, and most of them make worry. Therefore, it is necessary to organize physical education classes at least three times a week or daily at the faculty, as well as educational programs that theaches practical information about body mechanics and how to protect the back.

Our study has several limitations. The study participants were fourth year medical students on clinical training, and therefore, it was not possible to make a comparison among students of all six study years. Also, the survey has been undertaken in only one institution and should be expanded to include medical students from other universities in the country. Data about the experience of LBP, potential triggers, and impact of pain on daily functioning and mood were based on self-reports, and information bias is probably present. We did not collect data about BMI, smoking habits, and physical activity which future research should take into account.

\section{Conclusions}

The prevalence of LBP is high among Belgrade medical students and significantly affects their everyday functioning and mood. Female students have significantly higher 12-month and lifetime prevalence of LBP, compared to males.

\section{Conflicts of Interest}

The authors declare that they have no conflicts of interest.

\section{Acknowledgments}

This work was supported by the Ministry of Education and Science, Serbia, through Contract no. 175042 (2011-2017).

\section{References}

[1] D. Hoy, C. Bain, G. Williams et al., "A systematic review of the global prevalence of low back pain," Arthritis and Rheumatism, vol. 64, no. 6, pp. 2028-2037, 2012.

[2] B. Duthey, Priority Medicines for Europe and the World "A Public Health Approach to Innovation, Background Paper 6.24, Low back pain, 2013, WHO, Geneva, Switzerland, 2017, http://www.who.int/medicines/areas/priority_medicines/BP6_ 24LBP.pdf.

[3] D. Hoy, L. March, P. Brooks et al., "The global burden of low back pain: estimates from the Global Burden of Disease 2010 Study," Annals of the Rheumatic Disases, vol. 73, no. 6, pp. 968-974, 2014.

[4] A. L. Karunanayake, "Risk factors for chronic low back pain," Community Medicine and Health Education, vol. 4, no. 2, p. 271, 2014.

[5] J. A. A. Fernandes, C. V. Genebra, N. M. Maciel, A. Fiorelli, M. H. de Conti, and A. De Vitta, "Low back pain in schoolchildren: a cross-sectional study in a western city of São Paulo state, Brazil," Acta Ortopedica Brasileira, vol. 23, no. 5, pp. 235-238, 2015.
[6] D. Hoy, P. Brooks, F. Blyth, and R. Buchbinder, "The epidemiology of low back pain," Best Practice and Research. Clinical Rheumatology, vol. 24, no. 6, pp. 769-781, 2010.

[7] I. Calvo-Muñoz, A. Gómez-Conesa, and J. Sánchez-Meca, "Prevalence of low back pain in children and adolescents: a meta-analysis," BMC Pediatrics, vol. 13, no. 1, p. 14, 2013.

[8] R. N. V. Furtado, L. H. Ribeiro, B. A. Abdo, F. J. Descio, C. E. Martucci Jr., and D. C. Serruya, "Nonspecific low back pain in young adults: associated risk factors," Revista Brasileira de Reumatologia, vol. 54, no. 5, pp. 371-377, 2014.

[9] N. Aggarwal, T. Anand, J. Kishore, and G. K. Ingle, "Low back pain and associated risk factors among undergraduate students of a medical college in Delhi," Education for Health, vol. 26, no. 2, pp. 103-108, 2013.

[10] M. A. Alshagga, A. R. Nimer, L. P. Yan, I. A. Ibrahim, S. S. AlGhamdi, and S. A. Radman Al-Dubai, "Prevalence and factors associated with neck, shoulder and low back pains among medical students in a Malaysian Medical College," BMC Research Notes, vol. 6, no. 1, p. 244, 2013.

[11] D. R. Smith, N. Wei, T Ishitake, and R. S. Wang, "Musculoskeletal disorders among Chinese medical students," Kurume Medical Journal, vol. 52, no. 4, pp. 139-146, 2005.

[12] A. Falavigna, A. R. Teles, T. Mazzocchin et al., "Increased prevalence of low back pain among physiotherapy students compared to medical students," European Spine Journal, vol. 20, no. 3, pp. 500-505, 2011.

[13] J. A. D. Andersson, "Problems of classification of low back pain," Rheumatology and Rehabilitation, vol. 16, no. 1, pp. 34-36, 1977.

[14] B. O. A. Adegoke, A.C. Odole, and A. A. Adeyinka, "Adolescent low back pain among secondary school students in Ibadan, Nigeria," African Health Sciences, vol. 15, no. 2, pp. 429-437, 2015.

[15] P. Moroder, A. Runer, H. Resch, and M. Tauber, "Low back pain among medical students," Acta Orthopaedica Belgica, vol. 77, no. 1, pp. 88-92, 2011.

[16] W. Yao, X. Mai, C Luo, F. Ai, and Q. Chen, “A cross-sectional survey of nonspecific low back pain among 2083 schoolchildren in China," Spine, vol. 36, no. 22, pp. 1885-1890, 2011.

[17] P. T. Hakala, A. H. Rimpelä, L. A. Saarni, and J. J. Salminen, "Frequent computer-related activities increase the risk of neck-shoulder and low back pain in adolescents," European Journal of Public Health, vol. 16, no. 5, pp. 536-541, 2006.

[18] D. R. Smith and P. A. Leggat, "Prevalence and distribution of musculoskeletal pain among Australian medical students," Journal of Musculoskeletal Pain, vol. 15, no. 4, pp. 39-46, 2007.

[19] G. Deng, Y. Zhang, H. Cai et al., "Effects of physical factors on neck or shoulder pain and low back pain of adolescents," Zhonghua Yi Xue Za Zhi, vol. 94, no. 43, pp. 3411-3415, 2014.

[20] N. Wedderkopp, P. Kjaer, L. Hestbaek, L. Korsholm, and C. de Leboeuf-Yde, "High-level physical activity in childhood seems to protect against low back pain in early adolescence," Spine Journal, vol. 9, no. 2, pp. 134-141, 2009.

[21] E. Sitthipornvorakul, P. Janwantanakul, N. Purepong, P. Pensri, and A. J. van der Beek, "The association between physical activity and neck and low back pain: a systematic review," European Spine Journal, vol. 20, no. 5, pp. 677-689, 2011.

[22] M. Tanaka, S. Fukuda, K. Mizuno, H. Kuratsune, and Y. Watanabe, "Stress and coping styles are associated with severe fatigue in medical students," Behavioral Medicine, vol. 35, no. 3, pp. 87-92, 2009.

[23] P. B. O'Sullivan, A. J. Smith, D. J. Beales, and L. M. Straker, "Association of biopsychosocial factors with degree of slump 
in sitting posture and self-report of back pain in adolescents: a cross-sectional study," Physical Therapy, vol. 91, no. 4, pp. 470-483, 2011.

[24] Q. Zhao, Y. Zhang, G. Deng et al., "Relationship between the incidence of chronic pain and academic pressure in high school students," Zhonghua Yi Xue Za Zhi, vol. 94, no. 48, pp. 3831-3835, 2014

[25] A. H. Alnojeidi, Gender Differences in Low Back Pain and Self Reported Muscle Strengthening Activity among U.S. Adults, UNF thesis and dissertations, Paper 616, 2015, University of North Florida, Jacksonville, FL, USA, 2017, http://digitalcommons.unf. edu/etd/616.

[26] K. Janowski, S. Steuden, and J. Kuryłowicz, "Factors accounting for psychosocial functioning in patients with low back pain," European Spine Journal, vol. 19, no. 4, pp. 613-623, 2010.

[27] A. Kędra, A. Kolwicz-Gańko, D. Sitarski, P. Ewertowska, and D. Czaprowski, "Low back pain and everyday functioning of students," Ortopedia Traumatologia Rehabilitacja, vol. 18, no. 1, pp. 31-39, 2016. 


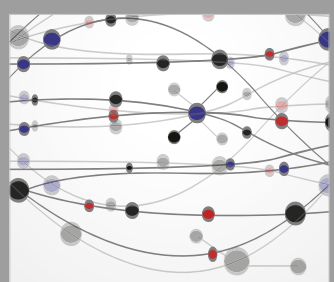

The Scientific World Journal
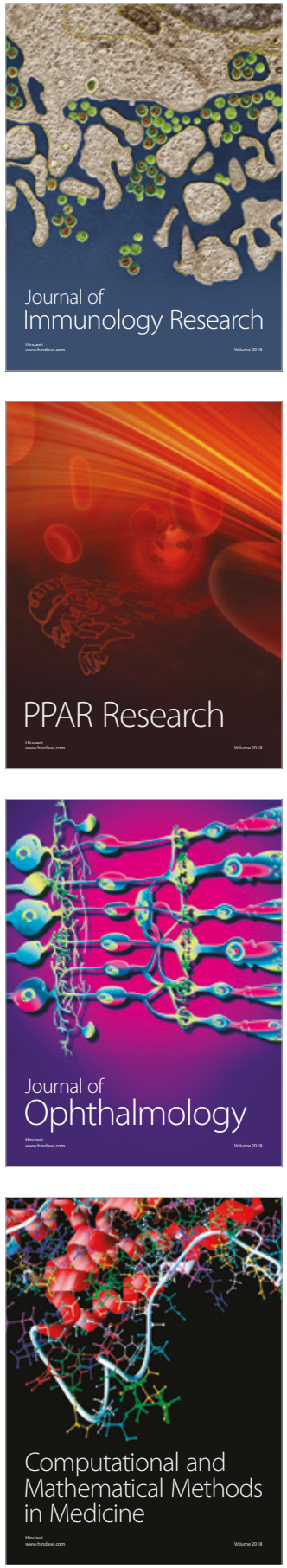

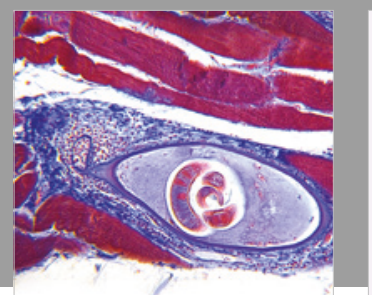

Gastroenterology Research and Practice

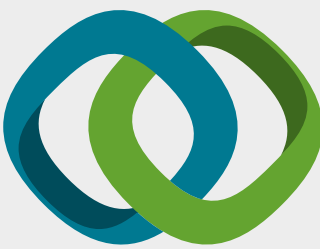

\section{Hindawi}

Submit your manuscripts at

www.hindawi.com
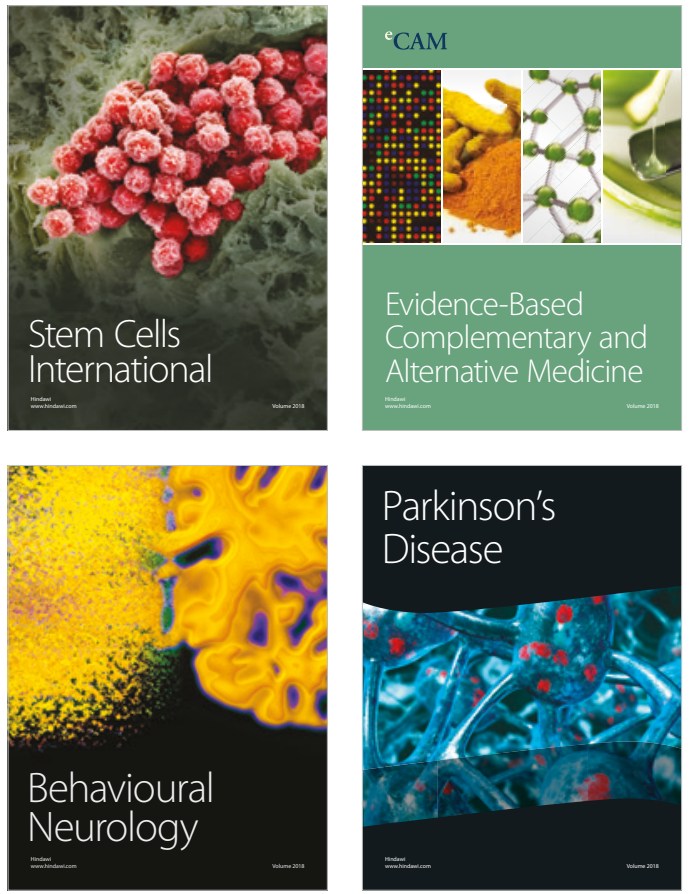

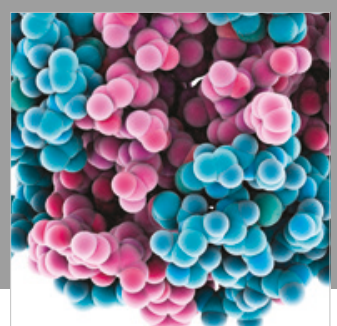

ournal of

Diabetes Research

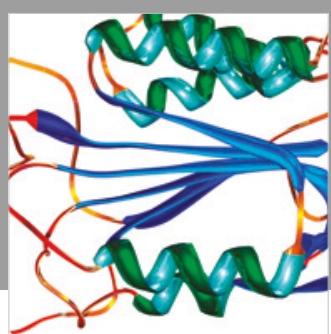

Disease Markers
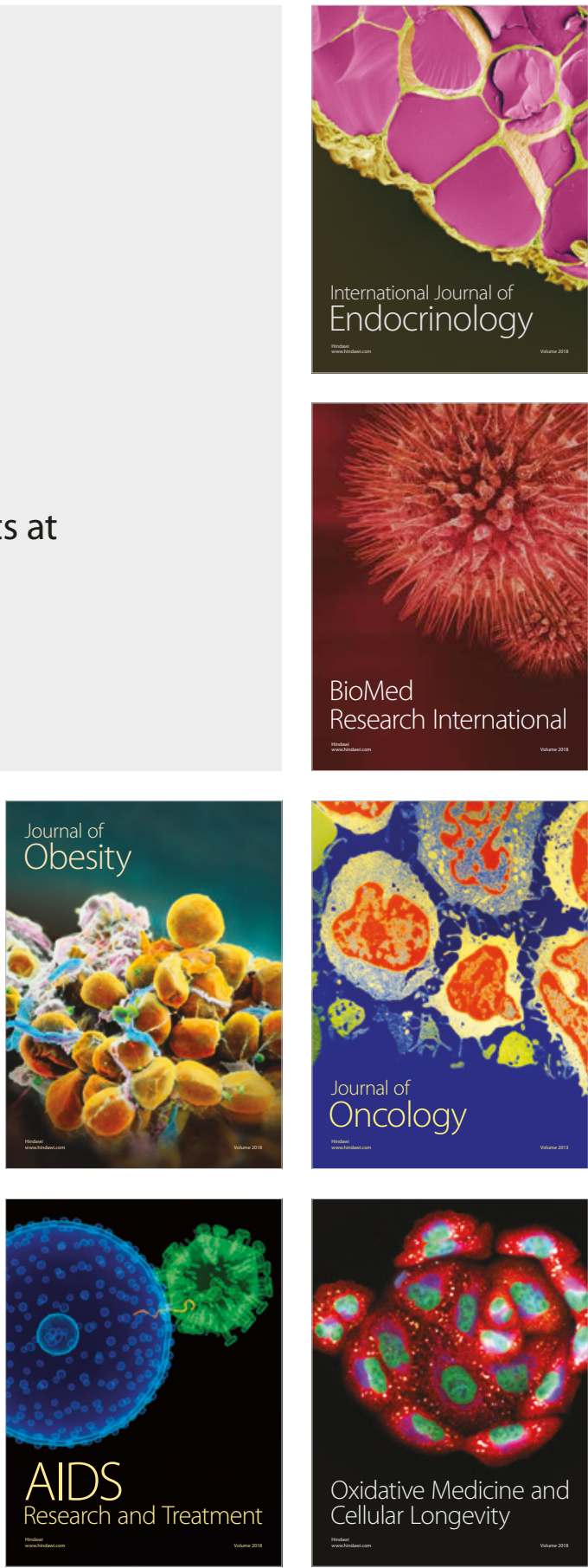